\title{
A Platform Approach in Servitization: How Platform Openness Can be Used to Control Solution Networks: An Abstract
}

\author{
Ruiqi Wei, Susi Geiger, and Roisin Vize
}

\begin{abstract}
How should a focal firm manage or orchestrate its network partners, and how much control is needed in this process? This is an enduring question in businessto-business (B2B) research, and it is one that attains heightened relevance in an era where digital platforms in industrial networks proliferate. This research explores how servitized solution providers leverage digital platform architectures and particularly platform openness to exert effective control over complex organizational networks. A multiple case study approach studies three companies with digital platforms that orchestrate solution networks in the LED and ICT industries. The findings show that the features of product modules (core or peripheral), service modules (relationship intensity and customization), and knowledge modules (explicit, tacit, and codified) have differential influence on the levels of platform openness. By setting platform openness of different subsystems accordingly, the solution providers can have different control benefits, including ensuring module quality, increasing offering variety, and reducing dependence from module providers and adjusting supply uncertainty. We contribute to the servitization literature by reconceptualizing the platform approach from a two-level perspective. We also deepen the field's understanding of the role of digital platforms in servitization from an architectural perspective.
\end{abstract}

R. Wei $(\bowtie) \cdot$ S. Geiger

University College Dublin, Dublin, Ireland

e-mail: ruiqi.wei@ucdconnect.ie; susi.geiger@ucd.ie

R. Vize

Dublin Institute of Technology, Dublin, Ireland

e-mail: roisin.vize@dit.ie 